\title{
Front Matter: Volume 11525
}

, "Front Matter: Volume 11525," Proc. SPIE 11525, SPIE Future Sensing Technologies, 1152501 (16 November 2020); doi: 10.1117/12.2588964

SPIE. Event: SPIE Future Sensing Technologies, 2020, Online Only 


\title{
PROCEEDINGS OF SPIE
}

\section{SPIE Future Sensing Technologies}

\author{
Masafumi Kimata \\ Joseph A. Shaw \\ Christopher R. Valenta \\ Editors
}

9-13 November 2020

Online Only, Japan

Sponsored and Published by

SPIE 
The papers in this volume were part of the technical conference cited on the cover and title page. Papers were selected and subject to review by the editors and conference program committee. Some conference presentations may not be available for publication. Additional papers and presentation recordings may be available online in the SPIE Digital Library at SPIEDigitalLibrary.org.

The papers reflect the work and thoughts of the authors and are published herein as submitted. The publisher is not responsible for the validity of the information or for any outcomes resulting from reliance thereon.

Please use the following format to cite material from these proceedings:

Author(s), "Title of Paper," in SPIE Future Sensing Technologies, edited by Masafumi Kimata, Joseph A. Shaw, Christopher R. Valenta, Proceedings of SPIE Vol. 11525 (SPIE, Bellingham, WA, 2020) Sevendigit Article CID Number.

ISSN: 0277-786X

ISSN: 1996-756X (electronic)

ISBN: 9781510638617

ISBN: 9781510638624 (electronic)

Published by

SPIE

P.O. Box 10, Bellingham, Washington 98227-0010 USA

Telephone +1 3606763290 (Pacific Time) · Fax +1 3606471445

SPIE.org

Copyright (c) 2020, Society of Photo-Optical Instrumentation Engineers.

Copying of material in this book for internal or personal use, or for the internal or personal use of specific clients, beyond the fair use provisions granted by the U.S. Copyright Law is authorized by SPIE subject to payment of copying fees. The Transactional Reporting Service base fee for this volume is $\$ 21.00$ per article (or portion thereof), which should be paid directly to the Copyright Clearance Center (CCC), 222 Rosewood Drive, Danvers, MA 01923. Payment may also be made electronically through CCC Online at copyright.com. Other copying for republication, resale, advertising or promotion, or any form of systematic or multiple reproduction of any material in this book is prohibited except with permission in writing from the publisher. The CCC fee code is 0277$786 \mathrm{X} / 20 / \$ 21.00$.

Printed in the United States of America by Curran Associates, Inc., under license from SPIE.

Publication of record for individual papers is online in the SPIE Digital Library.

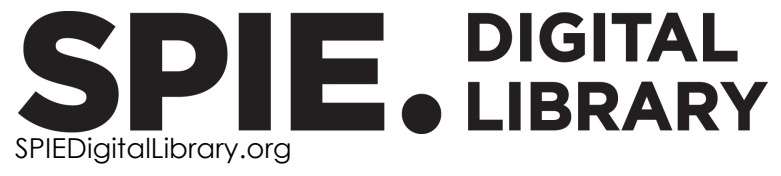

Paper Numbering: Proceedings of SPIE follow an e-First publication model. A unique citation identifier (CID) number is assigned to each article at the time of publication. Utilization of CIDs allows articles to be fully citable as soon as they are published online, and connects the same identifier to all online and print versions of the publication. SPIE uses a seven-digit CID article numbering system structured as follows:

- The first five digits correspond to the SPIE volume number.

- The last two digits indicate publication order within the volume using a Base 36 numbering system employing both numerals and letters. These two-number sets start with $00,01,02,03,04$, 05, 06, 07, 08, 09, OA, OB ... 0Z, followed by 10-1Z, 20-2Z, etc. The CID Number appears on each page of the manuscript. 


\title{
Contents
}

\author{
KEYNOTE SESSION
}

1152503 High-responsivity graphene infrared photodetectors based on photogating (Keynote Paper) [11525-101]

\section{SENSING FOR SAFETY/SECURITY}

1152504 Distance measurement based on two-photon absorption process in Si-avalanche photodiode with pulsed reference light [11525-2]

1152505 Sensitivity enhancement of distributed Brillouin fiber optic sensing using two-frequency pump and probe [11525-3]

1152506 Bridge monitoring and assessment by high-resolution satellite remote sensing technologies [11525-4]

1152507 Receiver operating characteristics analysis of Surface Enhanced Raman Spectroscopy (SERS) sensors [11525-5]

1152508 Real-time laser displacement measurement based on intensity correlation with phasemodulated signal and its measurement range extension [11525-6]

11525 OA Rapid quality assessment of food samples through biosensors [11525-8]

11525 OB FOTAS (Fiber Optic Based Acoustic Sensing System): requirements, design, implementation, tests and results [11525-9]

11525 OC Development of novel integrated in-line inspection techniques for pipeline inspection [11525-10]

\section{NEXT GENERATION TECHNOLOGY}

$11525 \mathrm{OE} \quad$ GaN laser diodes for quantum sensing [11525-12]

11525 OF Manifestation of an ultra-high sensitive fiber optic microbend sensor realized by shining a Bessel-Gauss beam [11525-13]

$115250 G$ Two entangled electrons (photons) microscopy [11525-14]

115250 Ol G-CoReCCD: a GPU-based simulator of the charge transport in fully-depleted CCDs [11525-16] 
$115250 \mathrm{~J}$ Characterization of surface plasmon resonance detection based on the colocalization effect inside metallic nanogap [11525-97]

LIDAR AND ACTIVE ELECTRO-OPTICAL SYSTEMS

$115250 \mathrm{M}$ Self-calibration of sensors using point cloud feature extraction [11525-17]

11525 ON A rail extraction algorithm based on the generalized neighborhood height difference from mobile laser scanning data [11525-18]

1152500 Building contour extraction from Airborne LIDAR point cloud for Digital Line Graphic [11525-19]

11525 OP The use of statistical mixture models to reduce noise in SPAD images of fog-obscured environments [11525-20]

$115250 Q \quad$ Object ranging and sensing by temporal cross-correlation measurement [11525-21]

$11525 \mathrm{OR} \quad$ Automatic laser power suggestion algorithm for active range gating system using Matlab and Scilab [11525-22]

\section{ARTIFICIAL INTELLIGENCE AND MACHINE LEARNING}

11525 OS Anomaly detection using ID convolutional neural networks for surface enhanced raman scattering [11525-23]

11525 OV SAMA-VTOL: a new unmanned aircraft system for remotely sensed data collection [11525-26]

$11525 \mathrm{OW} \quad$ Al based prediction of daily rainfall from satellite observation for disaster management [11525-27]

$115250 \mathrm{X}$ High-speed image-free target detection and classification in single-pixel imaging [11525-28]

11525 OY Optical multi-band detection of unmanned aerial vehicles with YOLO v4 convolutional neural network [11525-85]

\section{HYPERSPECTRAL AND ENVIRONMENTAL SENSING}

$11525 \mathrm{OZ}$ Hyperspectral band selection for food fraud application using self-organizing maps (SOM) [11525-29]

$1152510 \quad$ Hyperspectral imaging for VIS-SWIR classification of post-consumer plastic packaging products by polymer and color [11525-30]

1152512 Probe-based hyperspectral imager for crop monitoring [11525-32]

iv 
1152513 Standoff mid-infrared reflectance spectroscopy using quantum cascade laser for mineral identification [1 1525-33]

1152514 Suggestion for fine and coarse particle size and total volumes extraction methods from the two extinctions and PM information [1 1525-34]

1152515 Spatial water quality and plastic buoy of seaweed culture in coastal area, Indonesia [11525-35]

1152516 Research of periodical and non-periodical features of electric field components near Nalchik [11525-87]

\section{EO/IR SYSTEMS}

1152518 Design of passive athermalized objective lens in 1-5 $\mu \mathrm{m}$ wave band [1 1525-36]

1152519 A solution for future single-electron-counting fast-readout Skipper-CCD experiments: high channel density front-end electronics design and noise performance analysis [11525-37]

115251 A High performance Van der Waals heterostructure photodetectors based on black phosphorus [11525-38]

11525 1B The design of 3-mirror off-axis optical system with stray light analysis based on vector aberration theory [11525-39]

$115251 \mathrm{C} \quad$ AOTF transmission shaping for spectral polarimetric imaging [11525-40]

11525 ID Retrieval of the polarization ellipse of a THz-wave from precision measurements of lightshifts with cold trapped HD+ [11525-41]

\section{SENSOR PROCESSING AND DATA FUSION}

$115251 G \quad$ Optical measurements with stereoscopic shadows [11525-43]

$115251 \mathrm{H} \quad$ Light field image restoration in low-light environment [11525-44]

$1152511 \quad$ Fractional fourier transform based imaging algorithm for near-range radar and discretisation formats [11525-45]

$115251 \mathrm{~J} \quad$ A frequency spectrum-based processing framework for the assessment of tree root systems [11525-46]

11525 IL A spatiotemporal framework for human indoor activity monitoring [11525-48]

$115251 \mathrm{M}$ Clustering and visualization of long-term data on thunderstorms for the North Caucasus [11525-49]

$115251 \mathrm{~N}$ Spoof detection for fake biometric images using feature-based techniques [11525-50] 
1152510 Colour weight maps in visible and NIR image fusion [11525-51]

$115251 \mathrm{P} \quad$ How image capturing setups influence the quality of SfM reconstructions for wind turbine blade inspection [11525-52]

$115251 Q \quad$ Quantitative imaging of the resonator shape in the bundengan musical instrument [1 1525-53]

\section{POSTER SESSION}

11525 is Detection of acoustic signals from Distributed Acoustic Sensor data with Random Matrix Theory and their classification using Machine Learning [11525-55]

$115251 \mathrm{U} \quad$ Adaptive statistical inferential methods for information processing [11525-57]

$115251 \mathrm{~V} \quad$ A computational approach of interval estimation for information processing [11525-58]

$115251 \mathrm{~W} \quad$ Ultrafast NIR-SWIR lasers with transient stimulated Raman chirped pulse amplification for advanced LIDARs [11525-59]

$115251 X \quad$ Design considerations for "lifetime enhancement of long range continuous IR zoom lens" [1 1525-60]

$115251 Y \quad$ An investigation of deep learning algorithms applied to automated diagnosis for diabetic retinopathy [11525-61]

$1152512 \quad$ Real time monitoring of human respiration rate using infrared thermography [11525-62]

$1152521 \quad$ Bessel ultrasonic probe for large depth of field using conical acoustic lens [11525-64]

1152522 Fusion of infrared and visible images through multi-level co-occurrence filtering [1 1525-65]

1152523 High-resolution remote range detection method based on uncompensated FMCW sources for Iow-cost FMCW LIDAR [11525-66]

$1152525 \quad$ Very low cost LCD-based optical spatial phase modulator [11525-68]

$1152526 \quad$ Lightfield imaging for industrial applications [1 1525-69]

1152527 Compact four element triple field-of-view MWIR optical module [1 1525-70]

1152528 Assessment of spatial optical trapping with digital holographic sensing for biological microparticles studying [1 $1525-71]$

1152529 On the features of the interference of a set of single charged optical vortices for non-contact surface roughness analysis [11525-72]

$115252 \mathrm{E} \quad$ Fast focus-scanning optical-resolution photoacoustic microscopy with extended depth of field [1 1525-77] 
$115252 \mathrm{~F} \quad$ Large volumetric optical-resolution photoacoustic microscopy based on contourlet transform fusion [11525-78]

$115252 \mathrm{G}$ Post communication data transmission by entangled photons having high data security [11525-79]

$115252 \mathrm{H} \quad$ Several innovative methods to generate optical clock pulses by optical fiber coupler and optical saturable absorber [11525-80]

1152521 The test of the 4K sCMOS camera for astronomical application [11525-81]

$115252 \mathrm{~J} \quad$ Simulation study of interaction of pulse laser with brain using COMSOL [1 1525-82]

$115252 \mathrm{~K}$ Transmission of photons in mouse brain using Monte Carlo method: simulation study [11525-83]

$115252 \mathrm{~L}$ Distinction of bloods based on photoacoustic spectroscopy combined with PCA-LDA algorithm [11525-84]

11525 2M Bessel-beam photoacoustic microscopy based on k-space pseudospectral method: simulation study [11525-88]

$115252 \mathrm{~N}$ Deconvolution optical-resolution photoacoustic microscope for high-resolution imaging of brain [11525-89]

1152520 Optimization method to eliminate the influence of the conical acoustic lens on the transmission of laser beam using ZEMAX [11525-90]

$115252 \mathrm{P} \quad$ Denoising method for photoacoustic microscopy using deep learning [11525-91]

$115252 \mathrm{Q}$ Three-dimensional large volumetric photoacoustic microscopy using Airy-beam [11525-92]

$115252 \mathrm{R} \quad$ Multifocus optical-resolution photoacoustic microscope for large volumetric imaging using tunable acoustic gradient lens and optical delay method [1 1525-93]

$115252 S$ Performance characteristics and permittivity modeling of a surface plasmon resonance sensor for metal surface monitoring in a synthetic maritime environment [11525-94]

$115252 \mathrm{~T} \quad$ Environmental temperature and material characterisation of planar evanescent microwave sensors for environmental analysis [11525-95]

$115252 \mathrm{U}$ Experimental modelling with theoretical validation of liquid crystal display elements for UAV optimal (optical) stealth [11525-96]

$115252 \mathrm{~V}$ Crop seed classification based on a real-time convolutional neural network [11525-98]

11525 2W Developing the kinematic model of the EOS scanning [11525-99] 
Proc. of SPIE Vol. $115251152501-8$

Downloaded From: https://www.spiedigitallibrary.org/conference-proceedings-of-spie on 25 Apr 2023
Terms of Use: https://www.spiedigitallibrary.org/terms-of-use 